\title{
Surface display for metabolic engineering of industrially important acetic acid bacteria
}

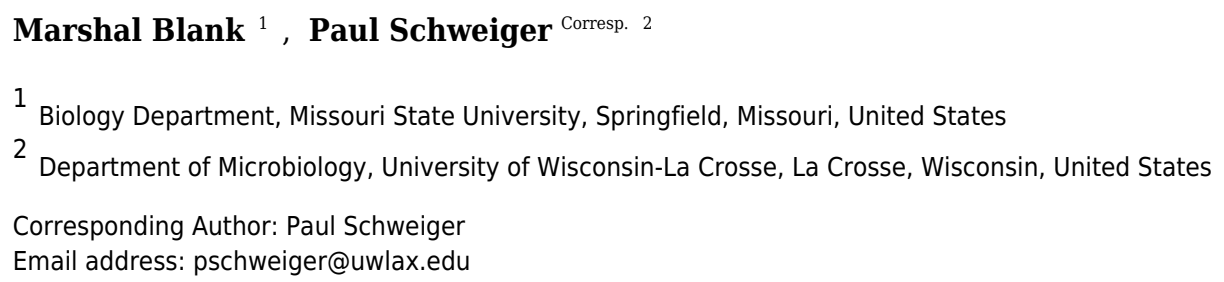

Acetic acid bacteria have unique metabolic characteristics that suit them for a variety of biotechnological applications. They possess an arsenal of membrane-bound dehydrogenases in the periplasmic space that are capable of regiospecific and enantioselective partial oxidations of sugars, alcohols, and polyols. The resulting products are deposited directly into the medium where they are easily recovered for use as pharmaceutical precursors, industrial chemicals, food additives, and consumer products. Expression of extracytoplasmic enzymes to augment the oxidative capabilities of acetic acid bacteria is desired but is challenging due to the already crowded inner membrane. To this end, an original surface display system was developed to express recombinant enzymes at the outer membrane of the model acetic acid bacterium Gluconobacter oxydans. Outer membrane protein OprF was used to deliver alkaline phosphatase PhoA to the cell surface. Constitutive high-strength p264 and moderate-strength p452 promoters were used to direct expression of the surface display system. This system was demonstrated for biocatalysis in whole-cell assays with the p264 promoter having a twofold increase in PhoA activity compared to the p452 promoter. Proteolytic cleavage of PhoA from the cell surface confirmed proper delivery to the outer membrane. Furthermore, a linker library was constructed to optimize surface display. A ridged (EAAAK), linker led to the greatest improvement, increasing PhoA activity by $69 \%$. This surface display system could be used both to extend the capabilities of acetic acid bacteria in current biotechnological processes, and to broaden the potential of these microbes in the production of value-added products. 
1 Surface display for metabolic engineering of industrially

2 important acetic acid bacteria

3 Marshal Blank $^{1}$ and Paul Schweiger ${ }^{2}$

$4 \quad{ }^{1}$ Missouri State University, Biology Department, 901 S. National Ave, Springfield, MO 65897

$5{ }^{2}$ University of Wisconsin-La Crosse, Department of Microbiology, 1725 State Street, La Crosse,

6 WI 54601

8 Corresponding Author:

$9 \quad$ Paul Schweiger ${ }^{2}$

1725 State St., La Crosse, WI 54601, USA

11 Email address: pschweiger@uwlax.edu 


\begin{abstract}
Acetic acid bacteria have unique metabolic characteristics that suit them for a variety of biotechnological applications. They possess an arsenal of membrane-bound dehydrogenases in the periplasmic space that are capable of regiospecific and enantioselective partial oxidations of sugars, alcohols, and polyols. The resulting products are deposited directly into the medium where they are easily recovered for use as pharmaceutical precursors, industrial chemicals, food additives, and consumer products. Expression of extracytoplasmic enzymes to augment the oxidative capabilities of acetic acid bacteria is desired but is challenging due to the already crowded inner membrane. To this end, an original surface display system was developed to express recombinant enzymes at the outer membrane of the model acetic acid bacterium Gluconobacter oxydans. Outer membrane protein OprF was used to deliver alkaline phosphatase PhoA to the cell surface. Constitutive high-strength p264 and moderate-strength p452 promoters were used to direct expression of the surface display system. This system was demonstrated for biocatalysis in whole-cell assays with the p264 promoter having a two-fold increase in PhoA activity compared to the $\mathrm{p} 452$ promoter. Proteolytic cleavage of PhoA from the cell surface confirmed proper delivery to the outer membrane. Furthermore, a linker library was constructed to optimize surface display. A ridged (EAAAK) $)_{1}$ linker led to the greatest improvement, increasing PhoA activity by $69 \%$. This surface display system could be used both to extend the capabilities of acetic acid bacteria in current biotechnological processes, and to broaden the potential of these microbes in the production of value-added products.
\end{abstract}

\title{
Introduction
}

Gluconobacter oxydans is an industrially important microbe belonging to the family

Acetobacteriaceae, commonly referred to as the acetic acid bacteria. G. oxydans is an incomplete oxidation specialist known for its ability to partially oxidize alcohols, polyols, and monosaccharides to produce a diverse array of aldehydes, ketones, and organic acids. These reactions occur in the periplasmic space, as G. oxydans possesses an arsenal of dehydrogenases bound to the inner membrane. Therefore, industrially valuable compounds are excreted directly into the growth medium, where they are easily obtained for use as food additives, pharmaceutical precursors, industrial chemicals, and consumer products (Deppenmeier \& Ehrenreich 2009; Deppenmeier et al. 2002; Prust et al. 2005). What is more, the membrane-bound dehydrogenases are both regiospecific and enantioselective, allowing the microorganism to produce chiral compounds from precursors containing multiple identical functional groups, such as sugars and polyols. Additionally, the membrane-bound dehydrogenases contain prosthetic groups that channel electrons to ubiquinone in the respiratory chain, which facilitates rapid oxidation of substrates (Deppenmeier \& Ehrenreich 2009; Prust et al. 2005). G. oxydans is also osmotolerant and acidophilic, which are desirable industrial characteristics (Olijve \& Kok 1979).

Acetic acid bacteria serve many roles in biotechnology, but $G$. oxydans is particularly important (Deppenmeier et al. 2002; Raspor \& Goranovic 2008). Currently, G. oxydans is used to produce L-sorbose, the precursor to vitamin C (Pappenberger \& Hohmann 2014; Yang \& Xu 2016) and 6-amino-6-desoxy-L-sorbose, the precursor to the antidiabetic drug miglitol (Schedel 2000). Additionally, this bacterium is used to produce, dihydroxyacetone and erythrulose, which are primarily used as tanning agents in cosmetics (De Muynck et al. 2007; Voss et al. 2010), as well 
as gluconate and gluconate derivatives, which serve as sequestering agents and drug precursors (De Muynck et al. 2007; Deppenmeier et al. 2002). Despite their widespread use in industry, progress towards metabolic engineering of acetic acid bacteria has been partially limited by the lack of molecular tools available for genetic manipulation of this group of microbes (Kallnik et al. 2010). Currently, constitutive expression vectors are available for gene expression (Kallnik et al. 2010; Shi et al. 2014; Zhang et al. 2010), and two markerless deletion systems have been developed (Kostner et al. 2013; Peters et al. 2013). The ability to produce recombinant enzymes for the modification of extracellular substrates has the potential to expand and compliment the natural incomplete-oxidative metabolism of acetic acid bacteria. Signal peptides that allow for periplasmic export are known (Kosciow et al. 2014), but the ability to produce additional enzymes bound to the cytoplasmic membrane is limited because this space is already crowded by the large number of native dehydrogenases (Guigas \& Weiss 2016). Production of extracellular enzymes is also challenging because G. oxydans lacks the machinery to secrete proteins across the outer membrane (Prust et al. 2005).

To overcome these limitations, a surface display system for expression of recombinant enzymes at the cell surface of G. oxydans and other acetic acid bacteria was designed. This molecular tool enables production of active enzymes with access to the extracellular space, bypassing the crowded inner membrane. Surface display involves translational fusion of a passenger protein with an anchor that innately localizes to the cell surface. Surface display offers several advantages for biocatalysis. Most importantly, substrates do not have to cross membrane barriers to interact with recombinant enzymes, and resulting products are deposited directly into medium, permitting simplified extraction without the need for cell lysis. Additionally, cells can be used for multiple rounds of biocatalysis, as they can be removed from a spent reaction by centrifugation and then resuspended in a solution containing new substrate. Lastly, surface display eliminates the need to purify enzymes (Schüürmann et al. 2014). To this end, a truncated version of outer membrane porin $\mathrm{F}(\mathrm{OprF})$ from Pseudomonas aeruginosa was translationally fused to alkaline phosphatase, PhoA, from Escherichia coli, and activity of the reporter enzyme was quantified in a whole-cell assay. PhoA was proteolytically cleaved from the cell, demonstrating that it was properly delivered to the outer leaflet of the outer membrane. Finally, the surface display system was optimized by testing the effects of various linkers on biocatalysis.

\section{Methods}

\section{Strains and Media}

Pseudomonas aeruginosa PAO1 (DSMZ 22644) was grown in tryptic soy broth (Becton Dickinson). Escherichia coli $10 \beta$ (New England Biolabs), herein E. coli, was grown in lysogeny broth $(1 \%$ tryptone, $0.5 \%$ yeast extract, $1 \% \mathrm{NaCl})$ with $100 \mu \mathrm{g} / \mathrm{mL}$ streptomycin added for strain maintenance. Gluconobacter oxydans $621 \mathrm{H}$, hereafter G. oxydans, was grown in yeast mannitol (YM) broth composed of $2 \%$ mannitol and $0.6 \%$ yeast extract, with $50 \mu \mathrm{g} / \mathrm{mL}$ cefoxitin added for strain maintenance. Plasmids were maintained by addition of $50 \mu \mathrm{g} / \mathrm{mL}$ kanamycin. Electrocompetent $G$. oxydans was prepared by growth in electroporation medium (Kallnik et al. 2010). After electroporation, $G$. oxydans cells were plated on yeast glucose calcium carbonate (YGC) agar ( $2 \%$ glucose, $1.5 \%$ agar, $0.7 \% \mathrm{CaCO}_{3}$, and $0.6 \%$ yeast extract) containing cefoxitin and kanamycin. 


\section{Materials and Molecular Techniques}

Standard molecular techniques were done according to manufacturer's protocols. Plasmid DNA was extracted using a GeneJet Plasmid Miniprep kit (ThermoFisher Scientific, Waltham, MA, USA) and genomic DNA was extracted using a GenElute Bacterial Genomic DNA kit (Millipore-Sigma, St. Louis, MO, USA). Phusion DNA polymerase and DreamTaq polymerase, FastDigest restriction enzymes, and T4 ligase were purchased from ThermoFisher Scientific. Factor Xa protease was purchased from New England Biolabs (Ipswich, MA, USA). Primers were purchased from either Eurofins Genomics (Louisville, KY, USA) or Integrated DNA Technologies (Coralville, IA, USA) (Table 1). DNA sequencing was done by Eurofins Genomics.

\section{Construction of a Surface Display System}

The sequence encoding the native signal peptide plus the first 188 amino acids of OprF (OprF188) was amplified from $P$. aeruginosa genomic DNA using primers oprF_F and oprF_R, containing extended EcoRI and Eco105I restriction sites, respectively. The resulting oprF18 $\overline{8}$ amplicon was digested with these enzymes and ligated into similarly-cut pBBR1p264-ST and pBBR1p452-ST to produce pBBR1p264-oprF-ST and pBBR1p452-oprF-ST (Table 1). The gene encoding alkaline phosphatase (PhoA) was amplified from E. coli genomic DNA using primers phoA_F and phoA_R, containing extended Eco105I and HindIII sites, respectively. Primer phoA_F was designed to exclude the native periplasmic signal sequence of PhoA. The phoA amplicon was digested with Eco105I and HindIII and ligated in-frame into similarly-cut vectors to produce pBBR1p264-oprF-phoA and pBBR1p452-oprF-phoA. Plasmids were transformed into $E$. coli and transformants were screened by colony PCR and confirmed by sequencing. Plasmids were then transformed into G. oxydans by electroporation (Kallnik et al. 2010; Kosciow et al. 2016; Kostner et al. 2013). Briefly, $100 \mathrm{~mL}$ of electroporation medium was inoculated with an overnight culture of $G$. oxydans and grown to an $\mathrm{OD}_{600 \mathrm{~nm}}$ of $0.8-1.0$. The culture was placed on ice for $20 \mathrm{~min}$, and chilled cells were harvested by centrifugation at 2,000 $\times g$ for $10 \mathrm{~min}$ at $4^{\circ} \mathrm{C}$. Cells were washed three times with 50-100\% volume of $1 \mathrm{mM} \mathrm{HEPES}$, with centrifugation at $4,000 \times g$ for $10 \mathrm{~min}$ at $4^{\circ} \mathrm{C}$. Pellets were resuspended with HEPES and combined into a final volume of $800 \mu \mathrm{L}$, to which $200 \mu \mathrm{L}$ of glycerol was added. Cells were either used immediately or aliquoted, flash-frozen, and stored at $-80^{\circ} \mathrm{C}$. For electroporation, 40 $\mu \mathrm{L}$ of electrocompetent cells were combined with $1 \mu \mathrm{L}$ of plasmid DNA and pulsed with a field strength of $22 \mathrm{kV} / \mathrm{cm}$ using a BioRad MicroPulser. After a 6-16 h outgrowth in electroporation medium, transformed cells were plated on YGC agar containing kanamycin and cefoxitin. To incorporate a cleavable linker (CL) into the OprF188-PhoA fusion protein, a 5'-extended version of the PhoA gene, $C L-p h o A$, was amplified from $E$. coli genomic DNA using primers CLphoA_F and phoA_R. Primer CL-phoA_F encoded the amino acid sequence, Ile-Asp-Gly-Arg, recognized by Factor Xa protease (Nagai \& Thogersen 1987; Terpe 2003). The CL-phoA amplicon was cut with Eco105I and HindIII and ligated into similarly-cut pBBR1p452-oprF-ST to produce pBBR1p452-oprF-CL-phoA (Table 1). 


\section{Construction of a Linker Library for Surface Display}

A library of flexible (FL) and ridged (RL) linkers was assembled similar to Li et al. (2016). The inserts, oprF-FL1, oprF-FL2, oprF-RL1, and oprF-RL2, were amplified from the plasmid, pBBR1p264-oprF-ST, using the forward primer, oprF_F, and the respectively-named reverse primers (oprF-FL1_R, oprF-FL2_R, oprF-RL1_R, and oprF-RL2_R) containing either BamHI or NotI sites. The inserts, FL1-phoA, FL2-phoA, RL1-phoA, and RL2-phoA were amplified from the E. coli genome using the reverse primer, phoA_R, and the respectively-named forward primers (FL1-phoA_F, FL2-phoA_F, RL1-phoA_F, and RL2-phoA_F) containing either BamHI or NotI sites. The linker system inserts were cut with their corresponding restriction enzymes - all oprF 188 inserts were cut with EcoRI, all phoA inserts were cut with HindIII, all flexible linker $(F L)$ inserts were cut with BamHI, and all rigid linker $(R L)$ inserts were cut with NotI. In parallel, vector pBBR1p264-oprF-ST was cut with EcoRI and HindIII. The linker library inserts were ligated into a linearized vector in a combinatorial fashion to produce six plasmids comprising the linker library: pBBR1p264-oprF-FL1-phoA, pBBR1p264-oprF-FL2-phoA, pBBR1p264-oprF-FL3-phoA, pBBR1p264-oprF-RL1-phoA, pBBR1p264-oprF-RL2-phoA, and pBBR1p264-oprF-RL3-phoA (Table 1).

\section{Phosphatase Assays}

Alkaline phosphatase assays were done using a modified method of Kosciow et al. (2014). Experimental cultures were inoculated 1:100 from overnight cultures and grown to mid-late exponential phase $\left(\mathrm{OD}_{600}\right.$ of $0.9-1.1$ for E. coli and $0.6-0.9$ for $G$. oxydans $)$. Forty microliters of cells were mixed with $160 \mu \mathrm{L}$ of substrate buffer $\left(1 \mathrm{M}\right.$ Tris base, $10 \mathrm{mM} \mathrm{MnSO}_{4}, 10 \mathrm{mM} \mathrm{ZnSO}_{4}$, $1.25 \mathrm{mM} p$-nitrophenylphosphate, $\mathrm{pH} 8.0$ ) in a 96-well microplate. The reactions were incubated with shaking for $60 \mathrm{~min}$ at $30^{\circ} \mathrm{C}$ and the change of absorbance was monitored at $405 \mathrm{~nm}$ in a BioTek EL808 plate reader. Phosphatase activity was reported as absorbance change per hour, normalized by the optical density of the bacterial culture, $\Delta \mathrm{A}_{405} /\left(\mathrm{h} \times \mathrm{OD}_{600}\right)$.

\section{PhoA Localization Assay}

Localization of the passenger protein was conducted using a modified method Jiang and Boder (2010). YM broth was inoculated 1:100 with an overnight culture of G. oxydans harboring plasmid pBBR1p452-oprF-CL-phoA and grown to mid-late exponential phase and $500 \mu \mathrm{l}$ was centrifuged at 2,000 $\times \mathrm{g}$ for $5 \mathrm{~min}$. The pellet was resuspended in $200 \mu \mathrm{L}$ of Factor Xa buffer $\left(100 \mathrm{mM} \mathrm{NaCl}, 20 \mathrm{mM}\right.$ Tris-base, $2 \mathrm{mM} \mathrm{CaCl}_{2}, \mathrm{pH}$ 8.0) and Factor Xa protease was added to a final concentration of $20 \mathrm{ng} / \mu \mathrm{L}$. Samples were incubated overnight at $23^{\circ} \mathrm{C}$ with shaking. After incubation, samples were pelleted at 2,000 $\times \mathrm{g}$ for $5 \mathrm{~min}$, and supernatant was transferred to a new microcentrifuge tube. The supernatant was centrifuged at $16,100 \times g$ for $2 \mathrm{~min}$ to remove intact cells and $40-\mu \mathrm{L}$ aliquots were used to quantify phosphatase activity as described above.

\section{Growth Behavior}

YM broth was inoculated to an $\mathrm{OD}_{600}$ of 0.05 from overnight cultures of $G$. oxydans strains and $1 \mathrm{~mL}$ of inoculated broth was added to a 24 -well microplate. The plate was incubated at $30^{\circ} \mathrm{C}$ 
with shaking at $150 \mathrm{rpm}$ for up to $24 \mathrm{~h}$, and absorbance was monitored at $595 \mathrm{~nm}$ every $5 \mathrm{~min}$ in a Flurostar Optima plate reader (BMG Labtech, $\mathrm{GmbH}$ ).

\section{Statistical Analysis}

R Studio was used to perform statistical analyses and to generate box-and-whisker plots, strip charts, and growth curve graphics (R Core Team 2017). Data were analyzed by performing an analysis of variance (ANOVA) and a post-hoc Tukey's HSD test ( $\mathrm{q}=0.05$ ) unless otherwise noted. The R packages used in this study were dplyr, ggplot2, growthcurver, plyr, multcomp, and reshape 2 (Hothorn et al. 2008; Sprouffske \& Wagner 2016; Wickham 2007; Wickham 2009; Wickham 2011; Wickham \& François 2014).

\section{Results}

\section{Surface Display in G. oxydans}

To enable surface display in acetic acid bacteria, a truncated version of OprF (OprF188) was tested for its ability to localize the PhoA reporter enzyme to the cell surface of G. oxydans. PhoA was translationally fused to the C-terminal end of OprF188, and the resulting OprF188-PhoA fusion protein was produced via two expression vectors, one containing a high-strength promotor (p264) and the other containing a moderate-strength promotor (p452) (Kallnik et al. 2010). As a preliminary test, these surface display constructs were expressed in E. coli and phosphatase activity was quantified in a whole-cell assay (Fig. 1). The OprF188-PhoA surface display systems produced statistically significant absorbance changes compared to strains expressing the anchor protein alone when using both the high- $(\mathrm{q}<0.001)$ and moderate-strength $(\mathrm{q}<0.001)$ promoters, p264 and p452, respectively. Enzymatic rates were approximately six-fold higher in the p264-oprF-phoA system compared to the p452-oprF-phoA system.

In G. oxydans, the p264-oprF-phoA strain produced a mean absorbance change of $0.39 /\left(\mathrm{h} \times \mathrm{OD}_{600}\right)$, corresponding to a volume activity of $3.21 \mathrm{mU} /\left(\mathrm{mL} \times \mathrm{OD}_{600}\right)$, which was significantly greater than basal activity $(q<0.001)$ (Fig. 2$)$. This level of activity is approximately three-fold lower than that observed when the same construct was expressed in E. coli. The p452oprF-phoA strain produced a mean absorbance change of $0.20 /\left(\mathrm{hr} \times \mathrm{OD}_{600}\right)$ and a volume activity of $1.65 \mathrm{mU} /\left(\mathrm{mL} \times \mathrm{OD}_{600}\right)$, which was significantly higher than that of the control $(\mathrm{q}<0.001)$. In contrast to the high-strength promotor, there was no reduction in activity when OprF188-PhoA expression was directed by the moderate-strength promoter in G. oxydans rather than E. coli.

To verify that PhoA was exposed to the extracellular space, a cleavable linker was incorporated into the fusion protein sequence. The resulting construct, p452-oprF-CL-phoA, was transformed into G. oxydans and an assay to localize PhoA was done (see Methods). The mean level of phosphatase activity observed in the supernatant from cells treated with Factor Xa protease was higher than that from untreated cells (two-sample t-test, p<0.001) (Fig. 3). These data suggest that PhoA was released into the supernatant after cleavage, indicating that PhoA was attached to the outer membrane and oriented toward the medium. 


\section{Linker System Optimization}

To optimize surface display in acetic acid bacteria, a library of linkers was integrated into the OprF188-PhoA surface display systems. First, overhang PCR was used to add linker building blocks to $o p r F 188$ and $p h o A$. These building blocks encoded for either flexible or rigid linkers and contained either BamHI or NotI restriction sites, respectively. The modified oprF188 inserts contained abridged linker sequences at their 3' ends and the modified phoA inserts contained abridged linker sequences at their 5' ends. Therefore, complete linker sequences resulted from ligation of compatible insert dyads. The building blocks were assembled into the expression vector that showed the highest activity to create six constructs encoding fusion proteins varying in linker composition and linker length: Three containing flexible linkers (FL1, FL2, and FL3) composed of a (GGGGS) $)_{1-3}$ motif, and three containing rigid linkers (RL1, RL2, and RL3) composed of the $(\mathrm{EAAAK})_{1-3}$ motif.

The linker library was first expressed in E. coli and PhoA activity was quantified (Fig. 4). The flexible linkers had slight negative effects on enzyme activity. While there was no difference between the control lacking a linker and the fusion protein containing the small flexible linker (FL1) ( $\mathrm{q}=0.939)$, the medium (FL2) and large (FL3) flexible linkers led to a slight but statistically significant decrease in activity $(\mathrm{q}<0.001$ for each). In contrast, the small (RL1) and medium (RL2) rigid linkers did not have any effect on activity ( $q=0.071$ and 0.969 , respectively). The large rigid linker (RL3) led to a slight but statistically significant increase in enzymatic activity when compared to the control $(\mathrm{q}<0.001)$. However, there was no difference between the RL1 strain and the RL3 strain $(\mathrm{q}=0.692)$, suggesting that the higher activity observed for the RL3 strain was likely not biologically significant.

The linker systems had more pronounced effects on PhoA activity in G. oxydans compared to the subtle effects of the flexible and rigid linkers in E. coli (Fig. 5). While the small flexible linker (FL1) and the medium rigid linker (RL2) had no effect on activity when compared to the control lacking a linker ( $q=0.967$ and $q=0.765$, respectively), the large rigid linker (RL3) led to a 32\% reduction in activity $(\mathrm{q}<0.001)$. Interestingly, the small rigid linker (RL1) drastically improved PhoA activity $(\mathrm{q}<0.001)$, having a $69 \%$ increase in biocatalysis that corresponded to a volume activity of $5.42 \mathrm{mU} /\left(\mathrm{mL} \times \mathrm{OD}_{600}\right)$. Attempts to transform plasmids p264-oprF-FL2-phoA and p264-oprF-FL3-phoA into G. oxydans were unsuccessful, suggesting that the medium (FL2) and large (FL3) flexible linkers were toxic at high expression.

\section{Effect of Surface Display on Growth of G. oxydans}

To characterize the effects of protein production and surface engineering on the growth behavior of G. oxydans cells, a method was developed to follow the growth of recombinant $G$. oxydans strains using standard 24-well microplates, allowing automated monitoring of cell growth in a plate reader. Strains containing OprF188 surface display systems were compared to wildtype $G$. oxydans $621 \mathrm{H}$ growth (Fig. 6). When the high-strength p264 promoter was used, production of the OprF188 anchor protein without fusion to PhoA led to a statistically significant increase in mean doubling time $(97 \mathrm{~min})$ compared to wildtype cells $(56 \mathrm{~min})(\mathrm{q}<0.001)$ (Fig. 7). However, when the OprF188-PhoA fusion was expressed, the doubling time (52 $\mathrm{min}$ ) was not different than that of wildtype cells $(q=0.603)$. The presence of the small flexible linker (FL1) increased 
the doubling time (82 min) compared to the strain expressing the OprF188-PhoA fusion without a linker $(\mathrm{q}<0.001)$. Conversely, the presence of the small rigid linker (RL1) decreased doubling time $(27 \mathrm{~min})$ compared to the strain lacking the linker $(\mathrm{q}<0.001)$ and to wildtype cells $(\mathrm{q}<0.001)$. However, the lag time for this strain was approximately $8 \mathrm{~h}$ longer than that of wildtype cells (Fig 6). The medium rigid linker (RL2) did not affect doubling time (58 min) compared to the no-linker control strain $(\mathrm{q}=0.166)$ or wildtype cells $(\mathrm{q}=0.952)$ (Fig 7). Lastly, the large rigid linker (RL3) increased doubling time to $121 \mathrm{~min}$. Generally, the lag time was longer for recombinant strains and the final optical density was lower than that of wildtype $G$. oxydans, except for the p264-oprF-RL1-phoA containing strain (Fig. 6) that also produced the highest PhoA activity. Interestingly, doubling time was inversely proportional to PhoA activity (Fig. 7 and Fig. 5, respectively), suggesting that recombinant PhoA positively contributed to the growth of $G$. oxydans.

\section{Discussion}

In this study, the gene encoding PhoA was fused to OprF188 to test the ability of the anchor peptide to transport recombinant enzymes to the cell surface of acetic acid bacteria. The resulting constructs were expressed in the model acetic acid bacterium G. oxydans and biocatalysis was quantified in whole-cell reactions. Based on enzymatic activity, OprF188 localized active PhoA to the cell surface, regardless of expression level. Nascent PhoA has no activity in the cytoplasm as it does not fold properly unless secreted extracellularly where disulfide bonding takes place (De Geyter et al. 2016; Ehrmann et al. 1990; Hoffman \& Wright 1985; Manoil \& Beckwith 1985; Michaelis et al. 1983). The native periplasmic signal sequence was removed from PhoA before it was fused to OprF188, which contains an outer membrane signal peptide and is known to localize to the outer membrane (Lee et al. 2005a; Sugawara et al. 2012). The OprF188-PhoA fusion was produced using two expression vectors designed for protein production in $G$. oxydans, one containing a high-strength p264 promoter, and the other a moderate-strength p452 promoter. There was a two-fold difference in phosphatase activity produced by G. oxydans between the two promoters. This mirrors the three-fold difference in enzymatic activity reported previously (Kallnik et al. 2010).

Because PhoA is an innately periplasmic enzyme, its location needed to be verified to show that OprF188 can correctly target recombinant enzymes to the outer leaflet of the outer membrane in G. oxydans. To this end, a cleavable linker was integrated between OprF188 and PhoA as was done previously to validate another surface display systems (Jiang \& Boder 2010). If PhoA was exposed at the cell surface via OprF188, then PhoA should be removed from the outer membrane following treatment with Factor Xa protease, increasing phosphatase activity in the medium. The cleavable linker assay demonstrated that the level of phosphatase activity in the treated supernatant fractions was indeed higher than that in the untreated supernatant fractions $(p<0.001)$, which suggests that PhoA was present at the outer leaflet of the outer membrane.

In this study, we used a C-terminal truncated version of OprF, OprF188, containing 188 amino acids from the N-terminus of the original protein in its mature form. Valine 188 was previously determined to be the optimal fusion site for passenger proteins (Lee et al. 2005a). This anchor protein was previously used to localize a $49.9 \mathrm{kDa}$ lipase, which is comparable to the size of the $47 \mathrm{kDa}$ PhoA monomer (Bradshaw et al. 1981), to the outer membrane of E. coli (Lee et al. 
2005a) and Pseudomonas putida (Lee et al. 2005b). The first 24 amino acids of nascent OprF188 encodes a Sec-dependent signal peptide. OprF is an unusual outer membrane protein in that it is comprised of two domains: An N-terminal domain that forms a small, eight-stranded $\beta$-barrel, and a C-terminal globular domain that associates with the cell wall in the periplasm (Bodilis \& Barray 2006; Sugawara et al. 2012). Mature OprF188 consists of only the $\beta$-barrel domain with a C-terminal extracellular loop (Lee et al. 2005a). OprF is also unusual because the $\beta$-signal that is recognized by the $\beta$-barrel assembly complex to facilitate outer membrane integration, is located internally at the end of the $\beta$-barrel domain, rather than C-terminally (Gessmann et al. 2014; Sugawara et al. 2012). Thus, truncated OprF188 maintains its $\beta$-signal, allowing proper membrane integration (Lee et al. 2005a; Sugawara et al. 2012).

Interestingly, there have been many unsuccessful attempts to target PhoA to the cell surface of $E$. coli using $E$. coli outer membrane proteins as anchors. PhoA was fused to the ferrichrome outer membrane transporter FhuA (Coulton et al. 1988). While PhoA was associated with the outer membrane, it was not necessarily exposed to the outer surface. Similarly, the ferric enterobactin outer membrane transporter FepA localized PhoA to the outer membrane of $E$. coli, but it was periplasmically oriented (Murphy \& Klebba 1989). When a PhoA was fused to a lipoproteinOmpA hybrid, again the fusion protein was associated with the outer membrane but PhoA existed exclusively in the periplasm (Stathopoulos et al. 1996). Close inspection of these studies reveals that the $\beta$-signal was removed from FhuA, FepA, and OmpA upon C-terminal truncation. Therefore, deletion of the $\beta$-signal was likely sufficient to prevent proper outer membrane insertion by the $\beta$-barrel assembly complex in those studies. The use of OprF188 as an anchor to successfully display proteins on the cell surface in the current study and by others suggests that it is broadly functional as a surface display anchor protein in gram-negative bacteria, likely due to the preservation of the $\beta$-signal (Lee et al. 2005a; Lee et al. 2005b).

Despite their influence on fusion protein activity, the effect of linkers on bacterial surface display has not previously been investigated. While linkers are sometimes included in the design of surface display systems, their inclusion is rarely made explicit and even fewer studies offer any explanation as to why a particular linker sequence was chosen. Yet, linker sequences can play a vital role in the design of fusion proteins, affecting protein folding and production efficiency, and influencing enzyme activity (Chen et al. 2013; Li et al. 2016). Here, a library of linkers varying in both composition and length were integrated into a surface display system to explicitly test the effects of linkers on biocatalysis at the cell surface of two bacterial species. Two types of linkers were investigated in this study, flexible linkers and rigid linkers. Flexible linkers are composed of small, polar amino acids such as glycine and serine and form random coils, such as the $(\text { GGGGS })_{1-3}$ linker used here. Rigid linkers are often $\alpha$-helical, such as the (EAAAK $)_{1-3}$ linker used here (Chen et al. 2013; Li et al. 2016). Flexible linkers provide passive separation and permit interaction between the components of fusion proteins, while rigid linkers maintain a set distance and can prevent interaction between fusion protein domains ( $\mathrm{Li}$ et al. 2016). The linker library was first expressed in E. coli and, generally, the presence of linkers did not dramatically influence product yield. In contrast, the linkers caused pronounced effects on biocatalysis in $G$. oxydans. Fusion proteins containing the medium (FL2) and large (FL3) flexible linkers - 10 and 15 amino acids in length-were likely toxic to G. oxydans, as positive transformants were not obtained after multiple attempts. The fusion proteins containing the small flexible (FL1) and medium rigid (RL2) linkers had no influence on biocatalysis, whereas the large rigid (RL3) 
392 linker was deleterious. Optimization of the surface display system was achieved with the small

393 rigid linker (RL1), consisting of a single EAAAK pentapeptide, which improved phosphatase

394 activity by $69 \%$.

395

396

397

398

399

400

401

402

403

404

405

406

407

408

409

410

The disparate results of the linkers on E. coli and G. oxydans suggest that the effects of linkers on biocatalysis at the cell surface may be species-specific. E. coli and G. oxydans are phylogenetically distant, belonging to the Gammaproteobacteria and Alphaproteobacteria, respectively. There are likely differences in the composition of their outer membranes and thus the environment at the cell surface of these bacteria. It should be noted that the outer membrane composition of $G$. oxydans and other acetic acid bacteria remains largely uncharacterized, limiting direct comparison. Nevertheless, these differences may also be why phosphatase activity was overall higher in E. coli than in G. oxydans. Differences in promoter strength and/or efficiency of secretion (Choi \& Lee 2004) or outer membrane protein assembly by the $\beta$-barrel assembly complex (Browning et al. 2015; Sikora et al. 2017) may also play a role in the differences in the activities observed between E. coli and G. oxydans. Additionally, the differences in linker effects could also be passenger protein-specific. Overall, these results suggest that linker optimization is an important consideration for each surface display system used and for the specific host organism.

To determine the effects of protein production and surface engineering on the growth of $G$. oxydans, a novel method was developed for semi-high-throughput culturing of G. oxydans. The strain containing plasmid p264-oprF-ST had significantly slower growth compared to wildtype G. oxydans $621 \mathrm{H}$. It is possible that this growth defect was caused by the metabolic burden of protein production. Alternatively, the production of the OprF188 peptide may have overwhelmed secretory machinery, preventing sufficient amounts of required proteins from being processed. It is also possible that integration of the OprF188 anchor destabilizes outer membrane integrity. Interestingly, the p264-oprF-phoA strain did not exhibit a growth defect, suggesting that PhoA may enable recovery of the OprF188 phenotype. It may be that high expression of PhoA allowed cells to scavenge more phosphate from the medium, possibly allowing recovery from outer membrane lipid defects. Indeed, the small rigid linker (RL1) not only increased PhoA activity, but also improved the growth rate with concomitant increased lag time. PhoA activity seemed to be inversely proportional with doubling time, suggesting that inorganic phosphate availability may contribute to the observed growth phenotypes.

\section{Conclusion}

Surface display is potentially a powerful tool to enable metabolic engineering of G. oxydans and other industrially important acetic acid bacteria. G. oxydans currently has a limited ability to grow on disaccharides and polysaccharides, and instead relies on relatively expensive monomeric feedstocks (Kosciow et al. 2016). The ability to express enzymes at the outer membrane could be used to improve current bioprocesses by broadening the substrate range of this bacterium. Because this technique utilizes export machinery found in all gram-negative bacteria, the surface display constructs could be expressed in otherwise wildtype cells. Previously, a recombinant exoenzyme with a periplasmic signal peptide was efficiently released from cells only when a knockout strain of $G$. oxydans with a leaky outer membrane phenotype was used (Kosciow et al. 2016). Surface display could also be used in conjunction with 
438

immobilized G. oxydans cells to create stable bioreactors, such as those used in the production of dihydroxyacetone (Dikshit \& Moholkar 2016). In conclusion, a novel molecular tool for strain improvement of acetic acid bacteria was produced, and the $\operatorname{OprF} 188$ surface display system described herein is a significant first step towards outer membrane engineering of G. oxydans. Such molecular tools will enable engineering of this unique bacterium to improve and expand its ability to produce value-added products.

\section{Acknowledgements}

We thank Dr. Kyoungtae Kim and Dr. Laszlo Kovacs for lending their expertise and providing feedback on this project.

\section{References}

Bodilis J, and Barray S. 2006. Molecular evolution of the major outer-membrane protein gene (oprF) of Pseudomonas. Microbiology 152:1075-1088. 10.1099/mic.0.28656-0

Bradshaw RA, Cancedda F, Ericsson LH, Neumann PA, Piccoli SP, Schlesinger MJ, Shriefer K, and Walsh KA. 1981. Amino acid sequence of Escherichia coli alkaline phosphatase. Proc Natl Acad Sci U S A 78:34733477.

Browning DF, Bavro VN, Mason JL, Sevastsyanovich YR, Rossiter AE, Jeeves M, Wells TJ, Knowles TJ, Cunningham AF, Donald JW, Palmer T, Overduin M, and Henderson IR. 2015. Cross-species chimeras reveal BamA POTRA and beta-barrel domains must be fine-tuned for efficient OMP insertion. $\mathrm{Mol}$ Microbiol 97:646-659. 10.1111/mmi.13052

Chen X, Zaro JL, and Shen WC. 2013. Fusion protein linkers: property, design and functionality. Adv Drug Deliv Rev 65:1357-1369. 10.1016/j.addr.2012.09.039

Choi JH, and Lee SY. 2004. Secretory and extracellular production of recombinant proteins using Escherichia coli. Appl Microbiol Biotechnol 64:625-635. 10.1007/s00253-004-1559-9

Coulton JW, Reid GK, and Campana A. 1988. Export of hybrid proteins FhuA'-'LacZ and FhuA'-'PhoA to the cell envelope of Escherichia coli K-12. J Bacteriol 170:2267-2275.

De Geyter J, Tsirigotaki A, Orfanoudaki G, Zorzini V, Economou A, and Karamanou S. 2016. Protein folding in the cell envelope of Escherichia coli. Nature Microbiology 1:16107. 10.1038/nmicrobiol.2016.107

https://www.nature.com/articles/nmicrobiol2016107\#supplementary-information

De Muynck C, Pereira CS, Naessens M, Parmentier S, Soetaert W, and Vandamme EJ. 2007. The genus Gluconobacter oxydans: comprehensive overview of biochemistry and biotechnological applications. Crit Rev Biotechnol 27:147-171. 10.1080/07388550701503584

Deppenmeier U, and Ehrenreich A. 2009. Physiology of acetic acid bacteria in light of the genome sequence of Gluconobacter oxydans. J Mol Microbiol Biotechnol 16:69-80. 10.1159/000142895

Deppenmeier U, Hoffmeister M, and Prust C. 2002. Biochemistry and biotechnological applications of Gluconobacter strains. Appl Microbiol Biotechnol 60:233-242. 10.1007/s00253-002-1114-5

Dikshit PK, and Moholkar VS. 2016. Kinetic analysis of dihydroxyacetone production from crude glycerol by immobilized cells of Gluconobacter oxydans MTCC 904. Bioresour Technol 216:948-957. 10.1016/j.biortech.2016.06.042

Ehrmann M, Boyd D, and Beckwith J. 1990. Genetic analysis of membrane protein topology by a sandwich gene fusion approach. Proc Natl Acad Sci U S A 87:7574-7578.

Gessmann D, Chung YH, Danoff EJ, Plummer AM, Sandlin CW, Zaccai NR, and Fleming KG. 2014. Outer membrane beta-barrel protein folding is physically controlled by periplasmic lipid head groups and BamA. Proc Natl Acad Sci U S A 111:5878-5883. 10.1073/pnas.1322473111

Guigas G, and Weiss M. 2016. Effects of protein crowding on membrane systems. Biochimica et Biophysica Acta (BBA) - Biomembranes 1858:2441-2450. https://doi.org/10.1016/j.bbamem.2015.12.021

Hoffman CS, and Wright A. 1985. Fusions of secreted proteins to alkaline phosphatase: an approach for studying protein secretion. Proc Natl Acad Sci U S A 82:5107-5111. 
Hothorn T, Bretz F, and Westfall P. 2008. Simultaneous inference in general parametric models. Biom J 50:346-363. 10.1002/bimj.200810425

Jiang W, and Boder ET. 2010. High-throughput engineering and analysis of peptide binding to class II MHC. Proc Natl Acad Sci U S A 107:13258-13263. 10.1073/pnas.1006344107

Kallnik V, Meyer M, Deppenmeier U, and Schweiger P. 2010. Construction of expression vectors for protein production in Gluconobacter oxydans. J Biotechnol 150:460-465. 10.1016/j.jbiotec.2010.10.069

Kosciow K, Domin C, Schweiger P, and Deppenmeier U. 2016. Extracellular targeting of an active endoxylanase by a TolB negative mutant of Gluconobacter oxydans. J Ind Microbiol Biotechnol 43:989-999. 10.1007/s10295-016-1770-6

Kosciow K, Zahid N, Schweiger P, and Deppenmeier U. 2014. Production of a periplasmic trehalase in Gluconobacter oxydans and growth on trehalose. J Biotechnol 189:27-35. 10.1016/j.jbiotec.2014.08.029

Kostner D, Peters B, Mientus M, Liebl W, and Ehrenreich A. 2013. Importance of codB for new codA-based markerless gene deletion in Gluconobacter strains. Appl Microbiol Biotechnol 97:8341-8349. 10.1007/s00253-013-5164-7

Lee SH, Choi JI, Han MJ, Choi JH, and Lee SY. 2005a. Display of lipase on the cell surface of Escherichia coli using OprF as an anchor and its application to enantioselective resolution in organic solvent. Biotechnol Bioeng 90:223-230. 10.1002/bit.20399

Lee SH, Lee SY, and Park BC. 2005b. Cell surface display of lipase in Pseudomonas putida KT2442 using OprF as an anchoring motif and its biocatalytic applications. Appl Environ Microbiol 71:8581-8586. 10.1128/AEM.71.12.8581-8586.2005

Li G, Huang Z, Zhang C, Dong BJ, Guo RH, Yue HW, Yan LT, and Xing XH. 2016. Construction of a linker library with widely controllable flexibility for fusion protein design. Appl Microbiol Biotechnol 100:215-225. $10.1007 / \mathrm{s} 00253-015-6985-3$

Manoil C, and Beckwith J. 1985. TnphoA: a transposon probe for protein export signals. Proc Natl Acad Sci U S A 82:8129-8133.

Michaelis S, Inouye H, Oliver D, and Beckwith J. 1983. Mutations that alter the signal sequence of alkaline phosphatase in Escherichia coli. J Bacteriol 154:366-374.

Murphy CK, and Klebba PE. 1989. Export of FepA::PhoA fusion proteins to the outer membrane of Escherichia coli K-12. J Bacteriol 171:5894-5900.

Nagai K, and Thogersen HC. 1987. Synthesis and sequence-specific proteolysis of hybrid proteins produced in Escherichia coli. Methods Enzymol 153:461-481.

Olijve W, and Kok JJ. 1979. An analysis of growth of Gluconobacter oxydans in chemostat cultures. Archives of Microbiology 121:291-297.

Pappenberger G, and Hohmann HP. 2014. Industrial production of L-ascorbic Acid (vitamin C) and D-isoascorbic acid. Adv Biochem Eng Biotechnol 143:143-188. 10.1007/10_2013_243

Peters B, Junker A, Brauer K, Muhlthaler B, Kostner D, Mientus M, Liebl W, and Ehrenreich A. 2013. Deletion of pyruvate decarboxylase by a new method for efficient markerless gene deletions in Gluconobacter oxydans. Appl Microbiol Biotechnol 97:2521-2530. 10.1007/s00253-012-4354-z

Prust C, Hoffmeister M, Liesegang H, Wiezer A, Fricke WF, Ehrenreich A, Gottschalk G, and Deppenmeier U. 2005. Complete genome sequence of the acetic acid bacterium Gluconobacter oxydans. Nat Biotechnol 23:195-200. 10.1038/nbt1062

Raspor P, and Goranovic D. 2008. Biotechnological applications of acetic acid bacteria. Crit Rev Biotechnol 28:101124. 10.1080/07388550802046749

Schedel M. 2000. Oxidation of aminosorbitol with Gox in synthesis of deoxynojirimycin: Wiley-VHC, Weinheim (Germany).

Schüürmann J, Quehl P, Festel G, and Jose J. 2014. Bacterial whole-cell biocatalysts by surface display of enzymes: toward industrial application. Appl Microbiol Biotechnol 98:8031-8046. 10.1007/s00253-014-5897-y

Shi L, Li K, Zhang H, Liu X, Lin J, and Wei D. 2014. Identification of a novel promoter gHp0169 for gene expression in Gluconobacter oxydans. J Biotechnol 175:69-74. 10.1016/j.jbiotec.2014.01.035

Sikora AE, Wierzbicki IH, Zielke RA, Ryner RF, Korotkov KV, Buchanan SK, and Noinaj N. 2017. Structural and functional insights into the role of BamD and BamE within the $\beta$-barrel assembly machinery in Neisseria gonorrhoeae. Journal of Biological Chemistry. 10.1074/jbc.RA117.000437

Sprouffske K, and Wagner A. 2016. Growthcurver: an R package for obtaining interpretable metrics from microbial growth curves. BMC Bioinformatics 17:172. 10.1186/s12859-016-1016-7 
543

544

545

546

547

548

549

550

551

552

553

554

555

556

557

558

559

560

561
Stathopoulos C, Georgiou G, and Earhart CF. 1996. Characterization of Escherichia coli expressing an Lpp'OmpA(46-159)-PhoA fusion protein localized in the outer membrane. Appl Microbiol Biotechnol 45:112-119.

Sugawara E, Nagano K, and Nikaido H. 2012. Alternative folding pathways of the major porin OprF of Pseudomonas aeruginosa. FEBS J 279:910-918. 10.1111/j.1742-4658.2012.08481.x

Terpe K. 2003. Overview of tag protein fusions: from molecular and biochemical fundamentals to commercial systems. Appl Microbiol Biotechnol 60:523-533. 10.1007/s00253-002-1158-6

Voss J, Ehrenreich A, and Liebl W. 2010. Characterization and inactivation of the membrane-bound polyol dehydrogenase in Gluconobacter oxydans DSM 7145 reveals a role in meso-erythritol oxidation. Microbiology 156:1890-1899. 10.1099/mic.0.037598-0

Wickham H. 2007. Reshaping Data with the reshape Package.

Wickham H. 2009. ggplot2: Elegant Graphics for Data Analysis: Springer Publishing Company, Incorporated. Wickham H. 2011. The Split-Apply-Combine Strategy for Data Analysis.

Wickham H, and François R. 2014. dplyr: A Grammar of Data Manipulation.

Yang W, and Xu H. 2016. Industrial Fermentation of Vitamin C. In: JL R, and EJ V, eds. Industrial Biotechnology of Vitamins, Biopigments, and Antioxidants: Wiley-VCH Verlag GmbH \& Co. KGaA, 161-192.

Zhang L, Lin J, Ma Y, Wei D, and Sun M. 2010. Construction of a novel shuttle vector for use in Gluconobacter oxydans. Mol Biotechnol 46:227-233. 10.1007/s12033-010-9293-2 


\section{Table 1 (on next page)}

Plasmids and primers used for molecular cloning. 


\begin{tabular}{|c|c|c|}
\hline $\begin{array}{l}\text { Plasmid or } \\
\text { primer }\end{array}$ & Description or sequence $^{a}$ & $\begin{array}{l}\text { Source or } \\
\text { restriction } \\
\text { site }\end{array}$ \\
\hline \multicolumn{3}{|l|}{ Plasmids } \\
\hline pBBR1p264-ST & pBBR1p264 derivative containing a Strep-tag (ST) sequence & $\begin{array}{l}\text { Zeiser et al. } \\
2014\end{array}$ \\
\hline pBBR1p452-ST & pBBR1p452 derivative containing a ST sequence & $\begin{array}{l}\text { Deppenmeier } \\
\text { et al., unpub. }\end{array}$ \\
\hline $\begin{array}{l}\text { pBBR1p264- } \\
\text { oprF-ST }\end{array}$ & pBBR1p264-ST derivative expressing oprF188 from $P$. aeruginosa & This study \\
\hline $\begin{array}{l}\text { pBBR1p452- } \\
\text { oprF-ST }\end{array}$ & pBBR1p452-ST derivative expressing oprF188 from $P$. aeruginosa & This study \\
\hline $\begin{array}{l}\text { pBBR1p264- } \\
\text { oprF-phoA }\end{array}$ & $\begin{array}{l}\mathrm{pBBR} 1 \mathrm{p} 264-\mathrm{oprF}-\mathrm{ST} \text { derivative with } \mathrm{ST} \text { removed, expressing } p h o A \\
\text { from } E \text {. coli }\end{array}$ & This study \\
\hline $\begin{array}{l}\text { pBBR1p452- } \\
\text { oprF-phoA }\end{array}$ & $\begin{array}{l}\mathrm{pBBR} 1 \mathrm{p} 452-\mathrm{oprF}-\mathrm{ST} \text { derivative with } \mathrm{ST} \text { removed, expressing } p h o A \\
\text { from } E \text {. coli }\end{array}$ & This study \\
\hline $\begin{array}{l}\text { pBBR1p452- } \\
\text { oprF-CL-phoA }\end{array}$ & $\begin{array}{l}\text { pBBR1p452-oprF-phoA derivative with phoA removed, replaced by } \\
C L-p h o A \text { encoding a Factor Xa cleavable linker }\end{array}$ & This study \\
\hline $\begin{array}{l}\text { pBBR1p264- } \\
\text { oprF-FL1-phoA }\end{array}$ & $\begin{array}{l}\text { pBBR 1p264-oprF-ST derivative with } o p r F-S T \text { removed, replaced by } \\
o p r F-F L 1 \text { and } F L 1-p h o A \text { encoding a }(\mathrm{GGGGS})_{1} \text { flexible linker }\end{array}$ & This study \\
\hline $\begin{array}{l}\text { pBBR1p264- } \\
\text { oprF-FL2-phoA }\end{array}$ & $\begin{array}{l}\text { pBBR 1p264-oprF-ST derivative with } o p r F-S T \text { removed, replaced by } \\
o p r F-F L 2 \text { and } F L 1-p h o A \text { encoding a }(\mathrm{GGGGS})_{2} \text { flexible linker }\end{array}$ & This study \\
\hline $\begin{array}{l}\text { pBBR1p264- } \\
\text { oprF-FL3-phoA }\end{array}$ & $\begin{array}{l}\text { pBBR 1p264-oprF-ST derivative with } o p r F-S T \text { removed, replaced by } \\
o p r F-F L 2 \text { and } F L 2-p h o A \text { encoding a (GGGGS) })_{3} \text { flexible linker }\end{array}$ & This study \\
\hline $\begin{array}{l}\text { pBBR1p264- } \\
\text { oprF-RL1-phoA }\end{array}$ & $\begin{array}{l}\text { pBBR } 1 \mathrm{p} 264-o p r F-S T \text { derivative with } o p r F-S T \text { removed, replaced by } \\
o p r F-R L 1 \text { and } R L 1-p h o A \text { encoding a }(\mathrm{EAAAK})_{1} \text { rigid linker }\end{array}$ & This study \\
\hline $\begin{array}{l}\text { pBBR1p264- } \\
\text { oprF-RL2-phoA }\end{array}$ & $\begin{array}{l}\text { pBBR 1 p264-oprF-ST derivative with } o p r F-S T \text { removed, replaced by } \\
o p r F-R L 2 \text { and } R L 1 \text {-phoA encoding a }(\mathrm{EAAAK})_{2} \text { rigid linker }\end{array}$ & This study \\
\hline $\begin{array}{l}\text { pBBR1p264- } \\
\text { oprF-RL3-phoA }\end{array}$ & $\begin{array}{l}\text { pBBR1p264-oprF-ST derivative with } o p r F-S T \text { removed, replaced by } \\
o p r F-R L 2 \text { and } R L 2-p h o A \text { encoding a (EAAAK) })_{3} \text { rigid linker }\end{array}$ & This study \\
\hline \multicolumn{3}{|l|}{ Primers } \\
\hline oprF_F & ATGGAATTCAGGAGGTAATATTTatgaaactgaagaacaccttaggc & EcoRI \\
\hline oprF_R & ATCGTACGTAACTACCgacgttgtcgcaaacgecgtc & Eco105I \\
\hline phoA_F & AATTTACGTAcctgttctggaaaaccggg & Eco105I \\
\hline phoA_R & ATATAAGCTTtcatttcagccccagagcggc & HindIII \\
\hline CL-phoA_F & ATATTACGTA $A T C G A C G G C C G C$ GGCTCCcctgttctggaaaccgg & Eco105I \\
\hline oprF-FL1_R & AGA $\underline{G G A T C C G C C G C C G C C \text { gacgttgtcgcaaacgcc }}$ & BamHI \\
\hline oprF-FL2_R & $\begin{array}{l}\text { TAT } \overline{G G A T C C} G C C G C C G C C C G A G C C G C C G C C G C C \text { gacgttgtcgcaaa } \\
\text { cgec }\end{array}$ & BamHI \\
\hline oprF-RL1_R & $C T T G G C G G C C G C T T C$ gacgttgtcgcaaacgcc & NotI \\
\hline oprF-RL2-R & $C T T G \overline{G C G G C C G C} T T C C T T C G C C G C G G C T T C$ gacgttgtcgcaaacgcc & NotI \\
\hline FL1-phoA_F & 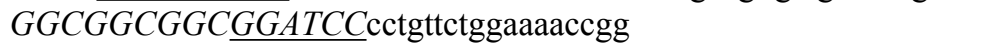 & BamHI \\
\hline FL2-phoA_F & 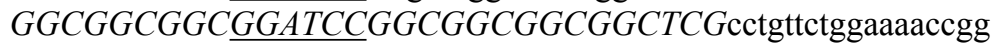 & BamHI \\
\hline RL1-phoA_F & $G A A \underline{G C G G C C G C C A A G \text { cctgttctggaaaaccgg }}$ & NotI \\
\hline RL2-phoA_F & GAAGCGGCCGC$C A A G G A A G C C G C G G C G A A G$ cetgttctggaaaaccgg & NotI \\
\hline
\end{tabular}

a The annealing portion of primers are shown in lowercase, synthetic additions uppercase, restriction sites underlined, linker sequences italicized, and ribosomal binding site bolded. 


\section{Figure 1}

OprF as a surface display anchor in E. coli.

The OprF188-PhoA fusion protein was produced in E. coli using the high-strength (p264) and moderate-strength (p452) promoters. Phosphatase activity was measured in whole-cell reactions. Respective strains producing only the anchor peptide fused to a Strep-tag (ST) served as negative controls. Rate of PhoA activity was monitored as $\triangle A 405 \mathrm{~nm} / \mathrm{h}$. OD600nm). Letters above the plot denote statistical groups determined by an ANOVA and post-hoc Tukey's HSD test. 


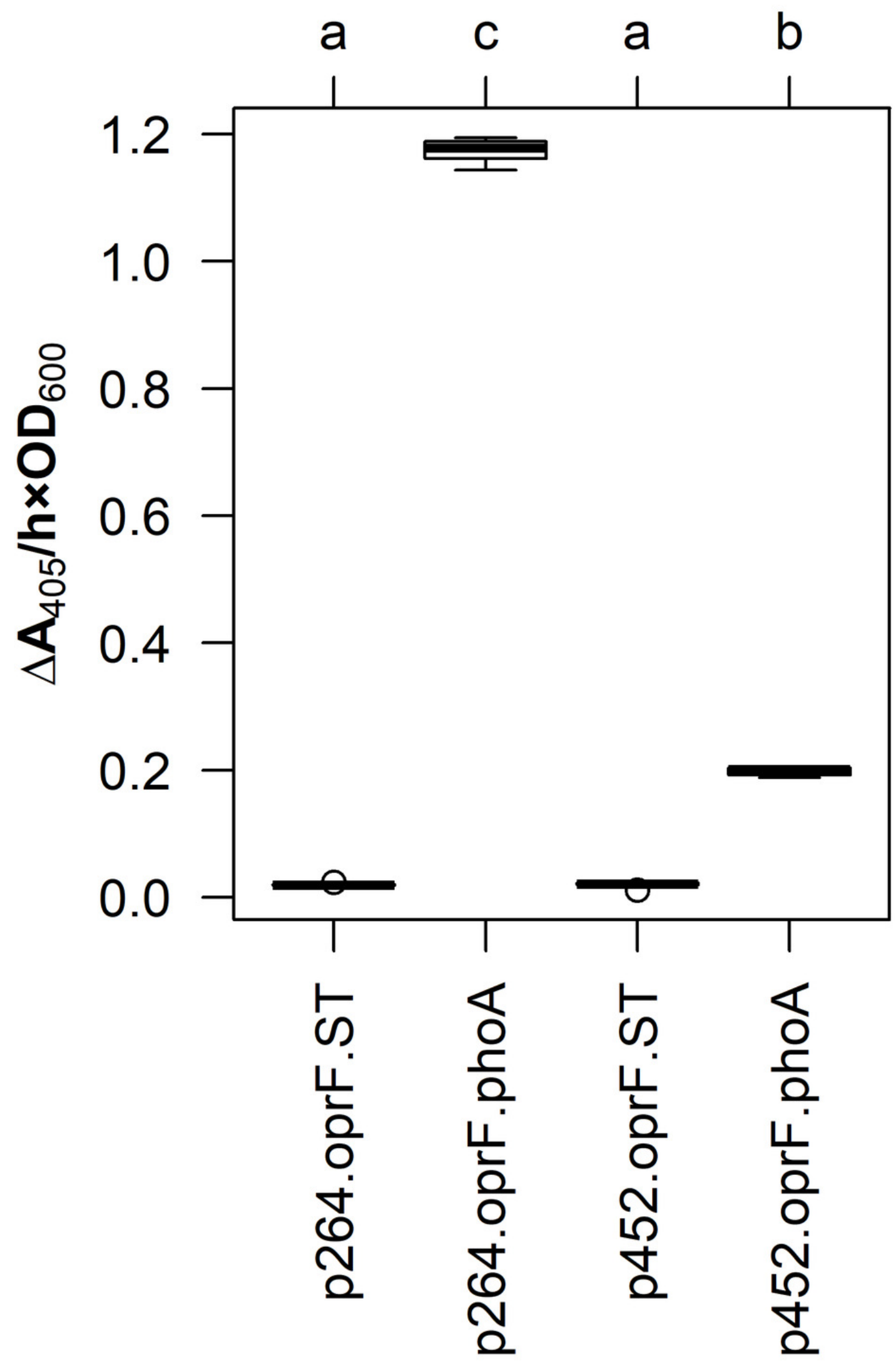

E. coli Strain $(\mathrm{N}=8)$ 


\section{Figure 2}

OprF as a surface display anchor in G. oxydans.

The OprF188-PhoA fusion protein was expressed in G. oxydans using the high-strength (p264) and moderate-strength ( $\mathrm{p} 452$ ) promoters. Phosphatase activity was measured in whole-cell reactions. Respective strains producing only the anchor peptide fused to a Streptag (ST) served as negative controls. Rate of PhoA activity was monitored as $\triangle A 405 \mathrm{~nm} /$ ( $h$. OD600nm). Letters above the plot denote statistical groups determined by an ANOVA and post-hoc Tukey's HSD test. 


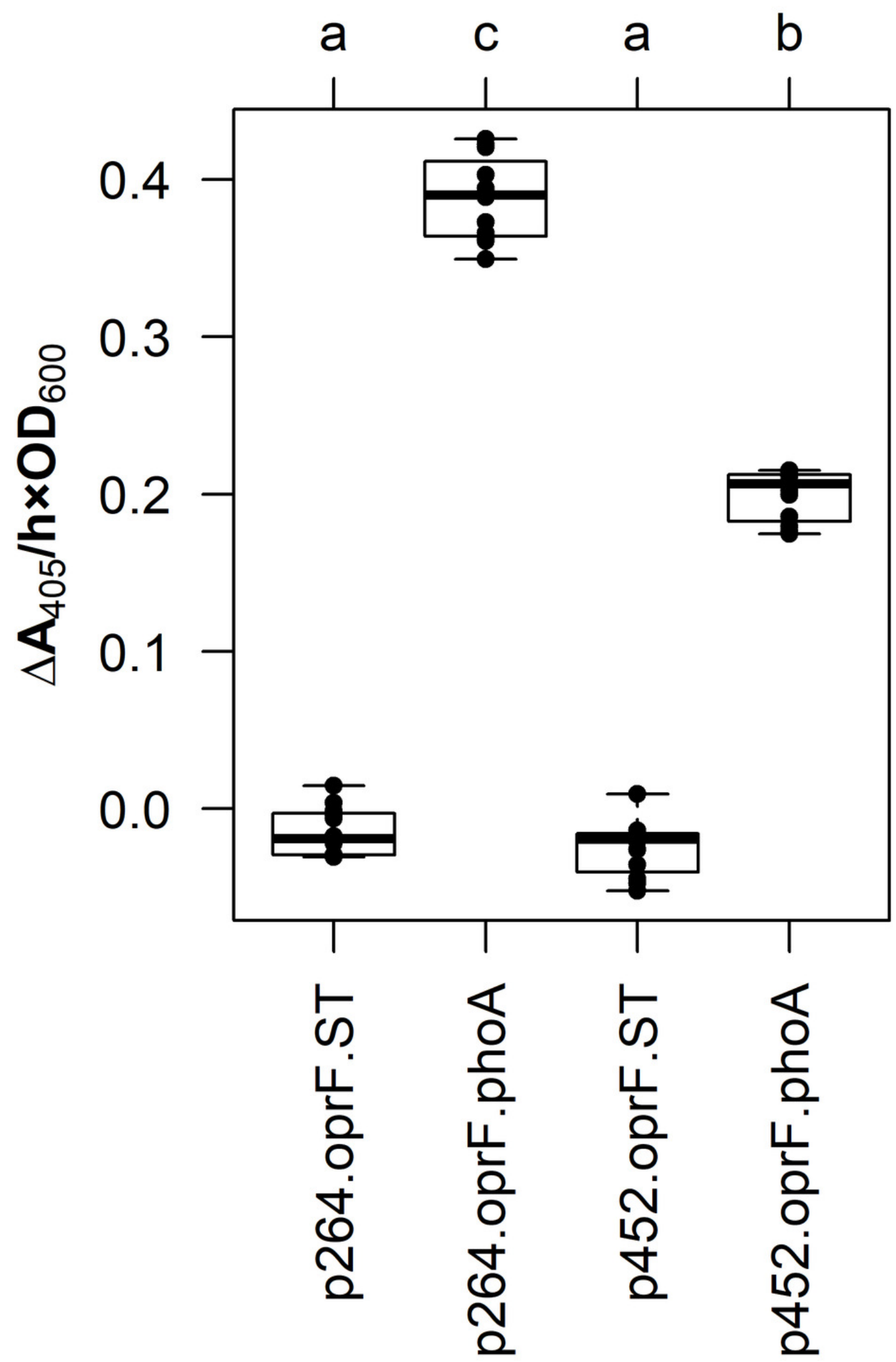

G. oxydans Strain $(\mathrm{N}=12)$ 


\section{Figure 3}

Cleavable linker assay.

To confirm proper localization of the passenger enzyme, a cleavable linker motif was incorporated into the OprF188-PhoA surface display system. Whole G. oxydans cells were treated with Factor Xa protease and the resulting supernatant (SN) was assayed for phosphatase activity. Rate of PhoA activity was monitored as $\triangle A 405 \mathrm{~nm} /(\mathrm{h} \cdot \mathrm{OD} 600 \mathrm{~nm}$ ). 


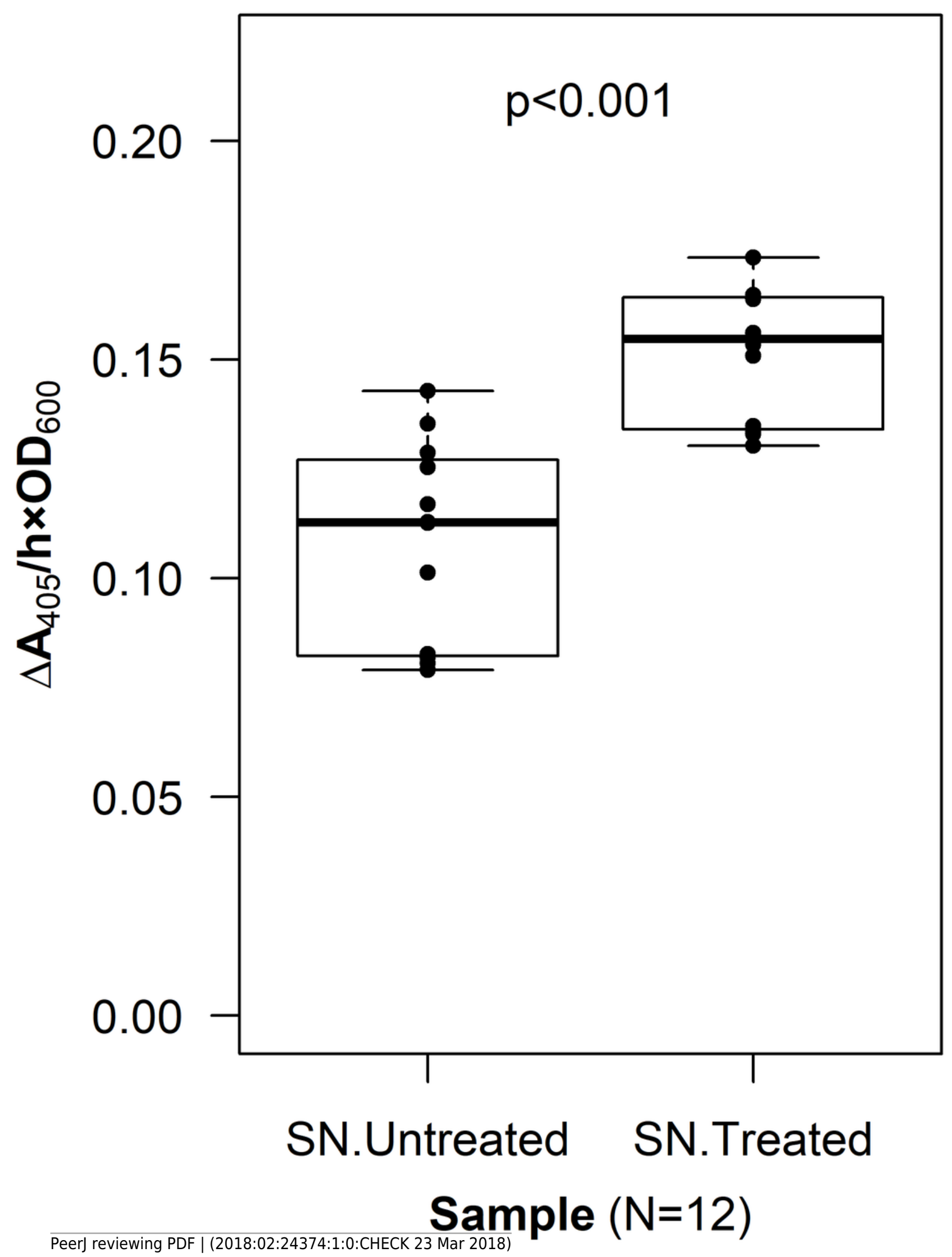




\section{Figure 4}

The effects of linkers on biocatalysis in E. coli.

To determine the effects of linkers on the surface display system, a library of flexible $\left(\text { GGGGS }_{1-3} \text { and rigid (EAAAK) }\right)_{1-3}$ linkers was integrated into the OprF188-PhoA fusion protein and PhoA activity was measured. Rate of PhoA activity was monitored as $\triangle A 405 \mathrm{~nm} /(\mathrm{h}$. OD600nm). Letters above the plot denote statistical groups determined by an ANOVA and post-hocTukey's HSD test. 


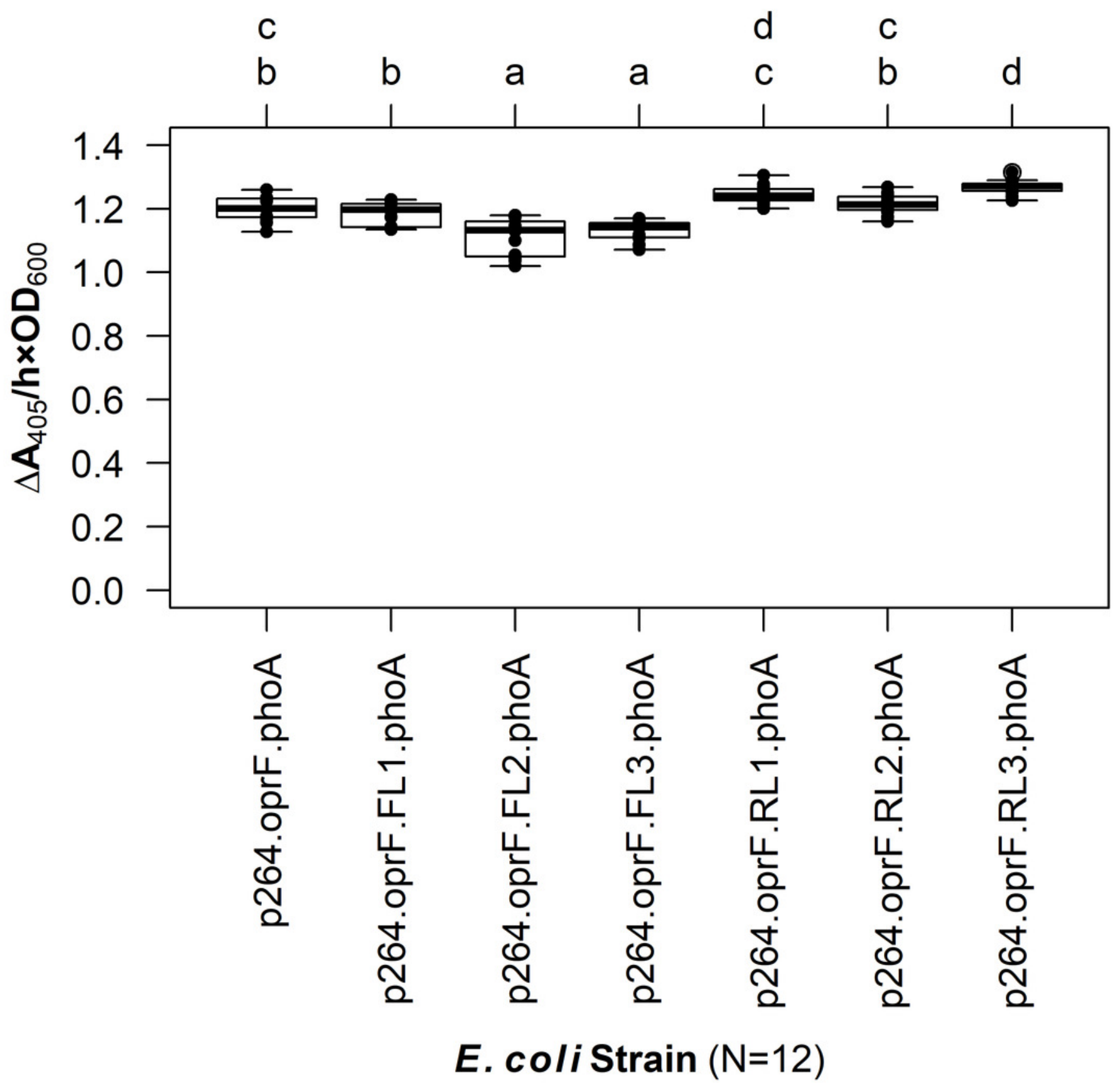




\section{Figure 5}

The effects of linkers on biocatalysis in G. oxydans.

A linker library consisting of flexible (GGGGS) ${ }_{1}$ and rigid (EAAAK) ${ }_{1-3}$ linkers was integrated into the OprF188-PhoA fusion protein and expressed in G. oxydans and the phosphatase activity was measured. Rate of PhoA activity was monitored as $\triangle A 405 \mathrm{~nm} /(\mathrm{h} \cdot 0 \mathrm{D} 600 \mathrm{~nm})$. Letters above the plot denote statistical groups determined by an ANOVA and post-hocTukey's HSD test. 


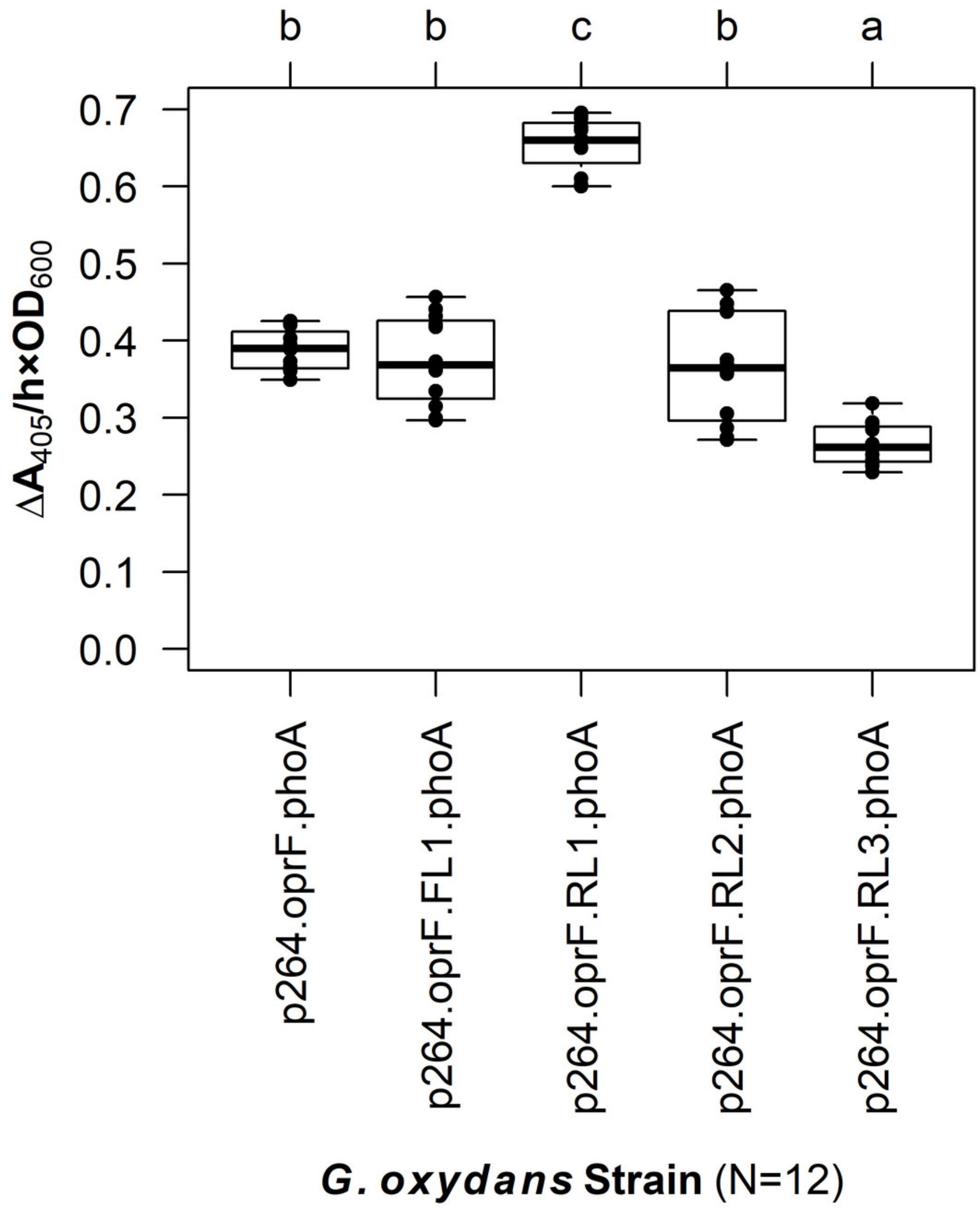


Figure 6

Growth behavior of recombinant $G$. oxydans strains.

Cells were cultured in 24-well microplates and the growth of recombinant G. oxydans $621 \mathrm{H}$ strains was compared to that of wildtype. Solid line, mean optical density; ribbon, $95 \% \mathrm{Cl} ; \mathrm{n}$ $=3$.

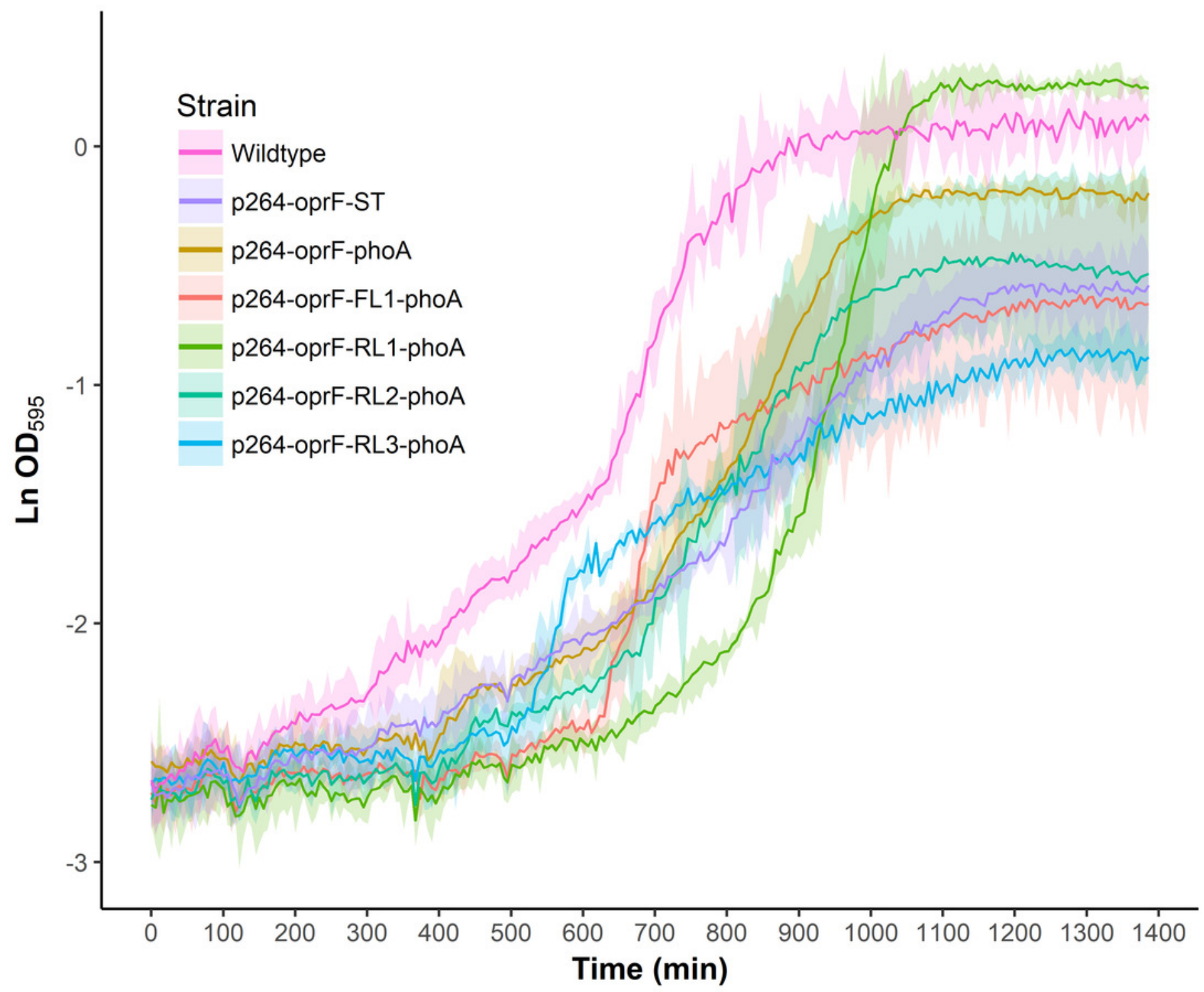


Figure 7

Doubling time of $G$. oxydans strains

Doubling time was calculated using the growthcurver $\mathrm{R}$ package. Letters above the plot denote statistical groups determined by an ANOVA and post-hocTukey's HSD test. 


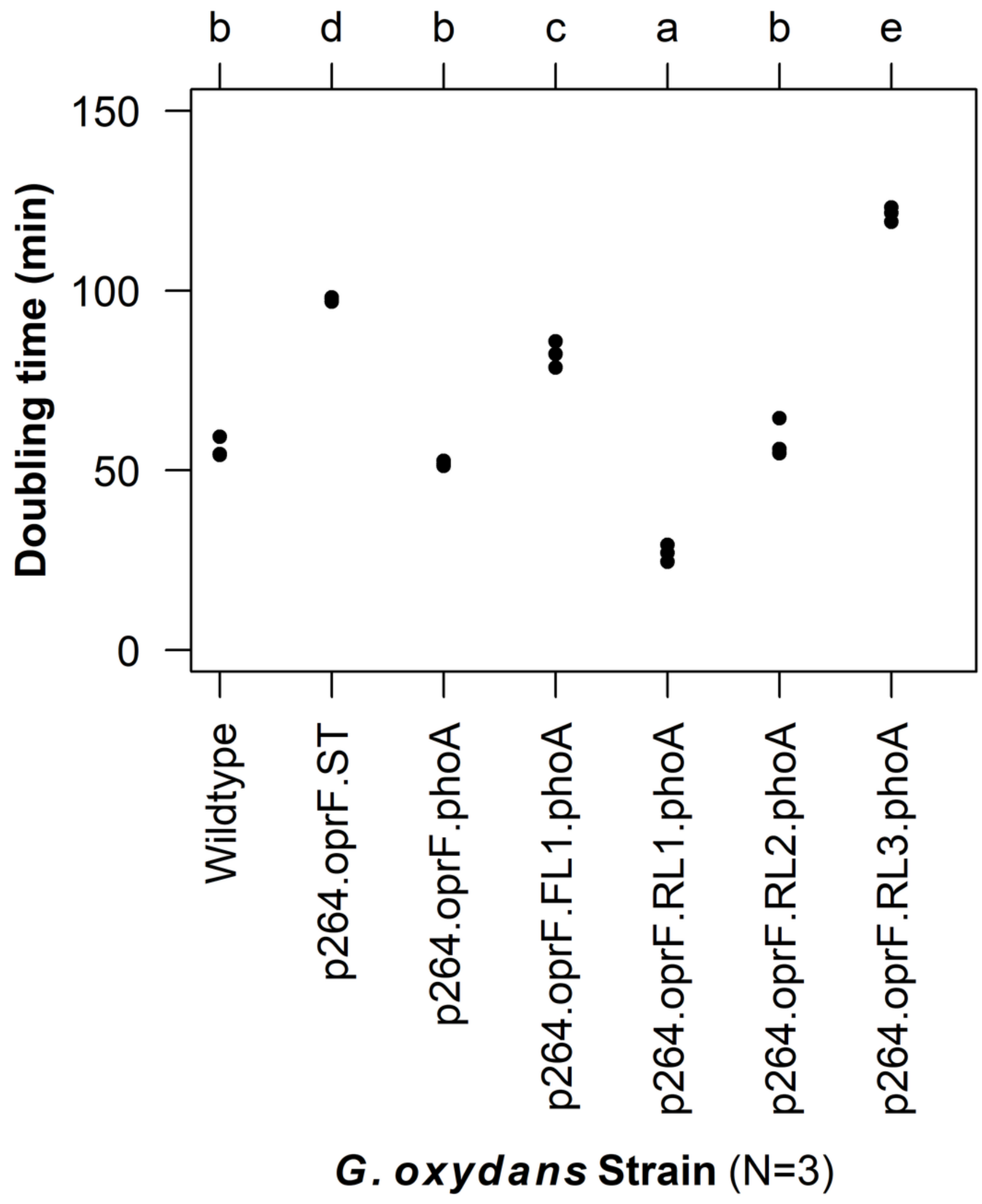

